\title{
CODESSA-Based Theoretical QSPR Model for Hydantoin HPLC-RT Lipophilicities
}

\author{
Alan R. Katritzky, ${ }^{*}$, Subbu Perumal, ${ }^{\S}$ Ruslan Petrukhin, ${ }^{\S}$ and Erich Kleinpeter ${ }^{\ddagger}$ \\ Center for Heterocyclic Compounds, Department of Chemistry, University of Florida, P.O. Box 117200, \\ Gainesville, Florida 32611-7200, and Institut fur Organische Chemie und Strukturanalytik, \\ Universitat Potsdam, Am Neuen Palais 10, D-14415 Potsdam, Germany
}

\author{
Received July 16, 2000
}

\begin{abstract}
A quantitative structure property relationship investigation was performed on the lipophilicities of a number of hydantoin derivatives as measured by the RP-HPLC retention times provided by Scholl et al. (Scholl, S.; Koch, A.; Henning, D.; Kempter, G.; Kleinpeter, E. Struct. Chem. 1999, 10, 355-366). The lipophilicities $(S)$ were correlated with the theoretical molecular descriptors of the hydantoins obtained using the CODESSA program from the AM1-optimized geometry and electron wave functions. This study discloses enhanced correlations of the lipophilicities with the molecular descriptors, wherein the influence of the entropy factor is found to predominate.
\end{abstract}

\section{INTRODUCTION}

Hydantoins find important applications as medicinals (e.g., as anticonvulsant drugs in the treatment of epilepsy) and as agrochemicals. ${ }^{1}$ The synthesis, ${ }^{2,3}$ structural aspects, ${ }^{4}$ and quantitative structure activity/property ${ }^{2}$ correlations of hydantoins have formed the subject of recent investigations.

Lipophilicity plays a vital role in physicochemical, environmental, and biological processes as it determines transport phenomena in vivo such as through the blood-brain membrane barrier. ${ }^{5}$ Classically, lipophilicity values have been expressed by partition coefficients, $P$, derived from distribution studies of a compound between water and an immiscible liquid such as $n$-octanol; however, measurement of lipophilicity from retention times in RP-HPLC has been considered to be a preferable alternative. ${ }^{5}$

Recently, Scholl et al. ${ }^{2}$ measured the RP-HPLC lipophilicities $(S)$ of a number of hydantoins and correlated them with the lipophilic surface parts $(A)$ of the Connolly surfaces in the single-parameter equation (eq 1 ).

$$
\begin{gathered}
S=-0.001 A-0.118 \\
\left(R^{2}=0.600, n=73, F=55.43, s^{2}=0.009\right)
\end{gathered}
$$

One of our groups has been active in QSPR/QSAR studies of several physicochemical and biological properties employing the CODESSA program. ${ }^{6} \mathrm{~A}$ series of investigations demonstrated that the CODESSA program, with its multitude of descriptors, was frequently able to provide improved correlations and give insight into the way in which structural features control physical properties. We have therefore now studied the HPLC-RT data of Scholl et al. ${ }^{2}$ in an attempt to find important factors contributing to hydantoin lipophilicity. The results are presented in this paper.

\section{METHODOLOGY}

Data Set. The series of hydantoin HPLC-RT (Table 1) reported by Scholl et al. ${ }^{2}$ was used in this QSPR study.

* Corresponding author. Phone: (352) 392-0554. E-mail: katritzky@ chem.ufl.edu.

$\S$ University of Florida.

$\doteqdot$ Universitat Potsdam.
Table 1. HPLC-RT Lipophilicity $(S)$ Data of Substituted Hydantoins

\begin{tabular}{rccccc}
\hline no. & $S$ & no. & $S$ & no. & $S$ \\
\hline $\mathbf{1}$ & & $\mathbf{2 6}$ & -0.197 & $\mathbf{5 1}$ & -0.147 \\
$\mathbf{2}$ & -0.157 & $\mathbf{2 7}$ & -0.183 & $\mathbf{5 2}$ & -0.170 \\
$\mathbf{3}$ & -0.157 & $\mathbf{2 8}$ & -0.222 & $\mathbf{5 3}$ & -0.191 \\
$\mathbf{4}$ & -0.174 & $\mathbf{2 9}$ & -0.224 & $\mathbf{5 4}$ & -0.165 \\
$\mathbf{5}$ & -0.180 & $\mathbf{3 0}$ & -0.233 & $\mathbf{5 5}$ & -0.174 \\
$\mathbf{6}$ & -0.144 & $\mathbf{3 1}$ & -0.202 & $\mathbf{5 6}$ & -0.184 \\
$\mathbf{7}$ & -0.142 & $\mathbf{3 2}$ & -0.190 & $\mathbf{5 7}$ & -0.174 \\
$\mathbf{8}$ & -0.145 & $\mathbf{3 3}$ & -0.173 & $\mathbf{5 8}$ & -0.182 \\
$\mathbf{9}$ & -0.141 & $\mathbf{3 4}$ & -0.210 & $\mathbf{5 9}$ & -0.193 \\
$\mathbf{1 0}$ & -0.186 & $\mathbf{3 5}$ & -0.164 & $\mathbf{6 0}$ & -0.191 \\
$\mathbf{1 1}$ & -0.157 & $\mathbf{3 6}$ & -0.200 & $\mathbf{6 1}$ & -0.190 \\
$\mathbf{1 2}$ & -0.168 & $\mathbf{3 7}$ & -0.210 & $\mathbf{6 2}$ & -0.225 \\
$\mathbf{1 3}$ & -0.211 & $\mathbf{3 8}$ & -0.191 & $\mathbf{6 3}$ & -0.233 \\
$\mathbf{1 4}$ & -0.209 & $\mathbf{3 9}$ & -0.197 & $\mathbf{6 4}$ & -0.211 \\
$\mathbf{1 5}$ & -0.227 & $\mathbf{4 0}$ & -0.222 & $\mathbf{6 5}$ & -0.208 \\
$\mathbf{1 6}$ & -0.193 & $\mathbf{4 1}$ & -0.209 & $\mathbf{6 6}$ & -0.197 \\
$\mathbf{1 7}$ & -0.178 & $\mathbf{4 2}$ & -0.260 & $\mathbf{6 7}$ & -0.236 \\
$\mathbf{1 8}$ & -0.190 & $\mathbf{4 3}$ & & $\mathbf{6 8}$ & -0.216 \\
$\mathbf{1 9}$ & -0.231 & $\mathbf{4 4}$ & -0.221 & $\mathbf{6 9}$ & -0.219 \\
$\mathbf{2 0}$ & -0.193 & $\mathbf{4 5}$ & -0.208 & $\mathbf{7 0}$ & -0.210 \\
$\mathbf{2 1}$ & -0.210 & $\mathbf{4 6}$ & -0.229 & $\mathbf{7 1}$ & -0.240 \\
$\mathbf{2 2}$ & -0.192 & $\mathbf{4 7}$ & -0.176 & $\mathbf{7 2}$ & -0.196 \\
$\mathbf{2 3}$ & -0.213 & $\mathbf{4 8}$ & -0.157 & $\mathbf{7 3}$ & -0.248 \\
$\mathbf{2 4}$ & -0.187 & $\mathbf{4 9}$ & -0.157 & $\mathbf{7 4}$ & -0.207 \\
$\mathbf{2 5}$ & -0.209 & $\mathbf{5 0}$ & -0.199 & $\mathbf{7 5}$ & -0.206 \\
\hline
\end{tabular}

Derivation of Descriptors and Regression Analyses. The structures of all the hydantoins (Figures 1 and 2) were drawn with the ISIS/Draw program. After preoptimization using molecular mechanics, the geometries of these compounds were further optimized using the semiempirical AM1 parametrization $^{7}$ of the MOPAC program. ${ }^{8}$ The resulting output files containing the refined geometry and electron wave function related descriptors formed the input for the CODESSA software package ${ }^{9}$ to calculate the molecular descriptors. This provided a number of constitutional, topological, geometrical, quantum-chemical, and thermodynamical molecular descriptors, the actual number of which varies for each compound, that were used for forming the descriptor matrix. This descriptor matrix with dimensions $792 \times 73$ was subsequently employed for correlating the lipophilicity values of the hydantoins. 


\begin{tabular}{|c|c|c|c|c|c|}
\hline No & $\mathbf{R}_{\mathbf{1}}$ & $\mathbf{R}_{\mathbf{2}}$ & No & $\mathbf{R}_{1}$ & $\overline{\mathbf{R}_{2}}$ \\
\hline 1 & $\mathrm{H}$ & $\mathrm{Me}$ & 26 & $\mathrm{Me}$ & 4-(t-Bu) $\mathrm{C}_{6} \mathrm{H}_{4}$ \\
\hline 2 & $\mathrm{H}$ & $\mathrm{Ph}$ & 27 & Et & 4- $\mathrm{MeOC}_{6} \mathrm{H}_{4}$ \\
\hline 3 & $\mathrm{H}$ & $\mathrm{PhCH}_{2}$ & 28 & $i-\mathrm{Pr}$ & 4- $\mathrm{MeOC}_{6} \mathrm{H}_{4}$ \\
\hline 4 & $\mathrm{H}$ & $\mathrm{PhCH}_{2} \mathrm{CH}_{2}$ & 29 & $\left(\mathrm{CH}_{3}\right)_{2} \mathrm{CHCH}_{2}$ & 4- $\mathrm{MeOC}_{6} \mathrm{H}_{4}$ \\
\hline 5 & $\mathrm{H}$ & c- $\mathrm{C}_{6} \mathrm{H}_{11} \mathrm{CH}_{2} \mathrm{CH}_{2}$ & 30 & $n-\mathrm{Bu}$ & 4- $\mathrm{MeOC}_{6} \mathrm{H}_{4}$ \\
\hline 6 & $\mathrm{Me}$ & cyclopropyl & 31 & $n$-Pr & 4- $\mathrm{MeOC}_{6} \mathrm{H}_{4}$ \\
\hline 7 & $\mathrm{Me}$ & $i-\operatorname{Pr}$ & 32 & $\mathrm{Et}$ & $4-\mathrm{FC}_{6} \mathrm{H}_{4}$ \\
\hline 8 & $\mathrm{Me}$ & $\left(\mathrm{CH}_{3}\right)_{2} \mathrm{CHCH}_{2}$ & 33 & Et & 2- $-\mathrm{FC}_{6} \mathrm{H}_{4}$ \\
\hline 9 & $\mathrm{Me}$ & $\mathrm{t}-\mathrm{Bu}$ & 34 & Et & $3-\mathrm{ClC}_{6} \mathrm{H}_{4}$ \\
\hline 10 & $\mathrm{Me}$ & $\left(\mathrm{CH}_{3}\right)_{2} \mathrm{CH}\left(\mathrm{CH}_{2}\right)_{2}$ & 35 & $\mathrm{Me}$ & 2- $\mathrm{ClC}_{6} \mathrm{H}_{4}$ \\
\hline 11 & $\mathrm{Ph}$ & $\mathrm{Me}$ & 36 & $\mathrm{Me}$ & $4-\mathrm{ClC}_{6} \mathrm{H}_{4}$ \\
\hline 12 & $\mathrm{Ph}$ & $\mathrm{Et}$ & 37 & Et & $4-\mathrm{ClC}_{6} \mathrm{H}_{4}$ \\
\hline 13 & $\mathrm{Ph}$ & $n$-Pr & 38 & $n$-Pr & 4- $\mathrm{ClC}_{6} \mathrm{H}_{4}$ \\
\hline 14 & $\mathrm{Ph}$ & $i$-Pr & 39 & $i-\operatorname{Pr}$ & $4-\mathrm{ClC}_{6} \mathrm{H}_{4}$ \\
\hline 15 & $\mathrm{Ph}$ & $n$-Bu & 40 & $n$-Bu & $4-\mathrm{ClC}_{6} \mathrm{H}_{4}$ \\
\hline 16 & $\mathrm{Ph}$ & cyclohexyl & 41 & $\left(\mathrm{CH}_{3}\right)_{2} \mathrm{CHCH}_{2}$ & $4-\mathrm{ClC}_{6} \mathrm{H}_{4}$ \\
\hline 17 & $\mathrm{Ph}$ & $\mathrm{MeOOC}$ & 42 & $n$-Heptyl & $4-\mathrm{ClC}_{6} \mathrm{H}_{4}$ \\
\hline 18 & $\mathrm{Ph}$ & EtOOC & 43 & $\mathrm{HOOCCH}_{2}$ & $4-\mathrm{ClC}_{6} \mathrm{H}_{4}$ \\
\hline 19 & $\mathrm{Ph}$ & $\mathrm{Ph}$ & 44 & $\mathrm{MeOOCCH}_{2}$ & 4- $\mathrm{ClC}_{6} \mathrm{H}_{4}$ \\
\hline 20 & $\mathrm{Ph}$ & $\mathrm{PhCH}_{2}$ & 45 & $\mathrm{Me}$ & 4- $\mathrm{BrC}_{6} \mathrm{H}_{4}$ \\
\hline 21 & $\mathrm{Et}$ & 4- $\mathrm{MeC}_{6} \mathrm{H}_{4}$ & 46 & $\mathrm{n}-\mathrm{Bu}$ & $4-\mathrm{BrC}_{6} \mathrm{H}_{4}$ \\
\hline 22 & $n-\operatorname{Pr}$ & 4- $\mathrm{MeC}_{6} \mathrm{H}_{4}$ & 47 & $\mathrm{Et}$ & $4-\mathrm{O}_{2} \mathrm{NC}_{6} \mathrm{H}_{4}$ \\
\hline 23 & $n$-Bu & 4- $\mathrm{MeC}_{6} \mathrm{H}_{4}$ & 48 & $\mathrm{Me}$ & 2-thienyl \\
\hline 24 & $i$-Pr & 4- $\mathrm{MeC}_{6} \mathrm{H}_{4}$ & 49 & $\mathrm{Me}$ & 2-furanyl \\
\hline 25 & $\left(\mathrm{CH}_{3}\right)_{2} \mathrm{CHCH}_{2}$ & 4- $\mathrm{MeC}_{6} \mathrm{H}_{4}$ & 50 & $\mathrm{Me}$ & 2-benzofuranyl \\
\hline
\end{tabular}

Figure 1. Structures of hydantoins 1-50.

The search of the representative set is local optimization within the discrete space of all descriptors; there is no guarantee that the global minimum is found. As it is difficult to perform a complete search for the best multilinear correlations with a multitude of descriptors, two different approaches, viz., the heuristic and the best multilinear regression methods (BMLR), have been employed in the present study to pick out the best descriptor combinations that explain the lipophilicities.

These correlation approaches differ in the method of arriving at the best possible blend of descriptor contributions among the available descriptors. The best multilinear regression method commences by correlating the given property employing two-parameter regression with pairs of orthogonal, with $R^{2}$ of intercorrelation less than 0.1 , descriptors. The pairs of descriptors with the highest correlation coefficients are selected for performing higher order regression treatments. Further inclusion of noncollinear descriptors in the regression is made, one descriptor after another, on the basis of the improved Fisher criterion at a given probability level upon successive addition of descriptors.
The heuristic method of the descriptor selection (HM), on the other hand, proceeds with a preselection of descriptors by eliminating

(i) those descriptors that are not available for each structure,

(ii) descriptors having a small deviation for all structures,

(iii) descriptors that provide a $F$-test's value below 1.0 in the one-parameter correlation, and

(iv) the descriptors whose $t$-values are less than the userspecified value, etc. ${ }^{9}$

This is followed by listing the remaining descriptors in decreasing order of correlation coefficient when used in oneparameter correlations. Subsequent procedure involves correlation of the given property with

(i) the top descriptor in the above list with each of the remaining descriptors and

(ii) the next one with each of the remaining descriptors, etc.

The best pairs as evidenced by the highest $F$-values in the two-parameter correlations are chosen and used for further inclusion of descriptors in a similar manner. 




51
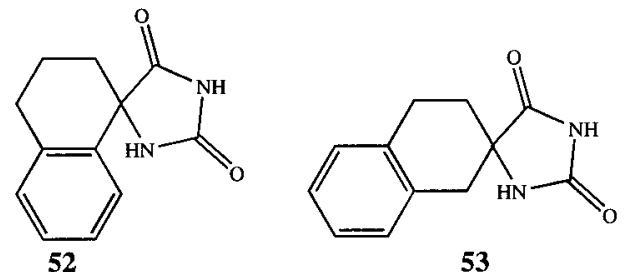

53
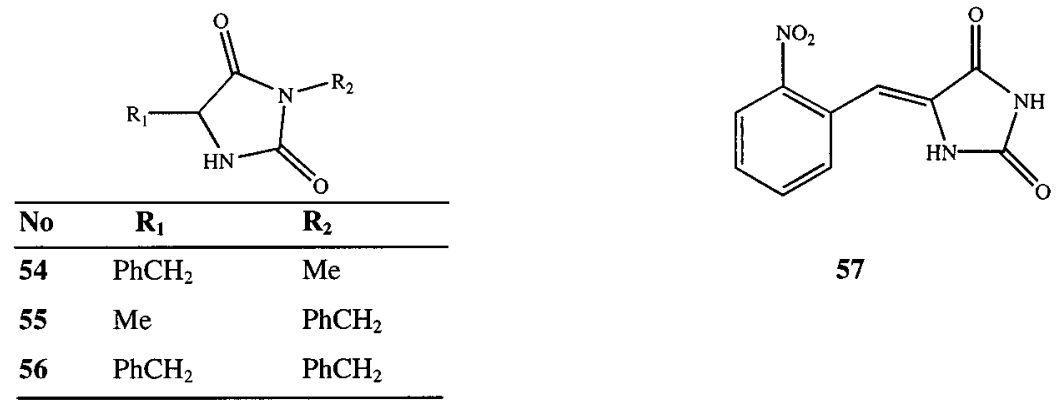

57

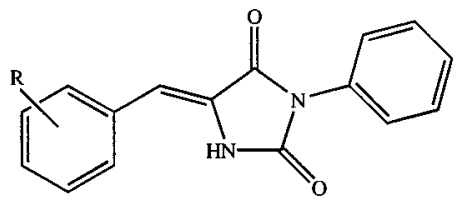

\begin{tabular}{llll}
\hline No & $\mathbf{R}$ & No & $\mathbf{R}$ \\
\hline $\mathbf{5 8}$ & $\mathrm{H}$ & $\mathbf{6 7}$ & $2,4-\mathrm{Cl}_{2}$ \\
$\mathbf{5 9}$ & $2-\mathrm{Me}$ & $\mathbf{6 8}$ & $2-\mathrm{Br}$ \\
$\mathbf{6 0}$ & $3-\mathrm{Me}$ & $\mathbf{6 9}$ & $3-\mathrm{Br}$ \\
$\mathbf{6 1}$ & $4-\mathrm{Me}$ & $\mathbf{7 0}$ & $4-\mathrm{Br}$ \\
$\mathbf{6 2}$ & $2,4,6-\mathrm{Me}_{3}$ & $\mathbf{7 1}$ & $4-\mathrm{F}_{3} \mathrm{C}$ \\
$\mathbf{6 3}$ & $4-\mathrm{i}-\mathrm{Pr}$ & $\mathbf{7 2}$ & $2-\mathrm{MeO}$ \\
$\mathbf{6 4}$ & $2-\mathrm{Cl}$ & $\mathbf{7 3}$ & $4-\mathrm{PhCH}_{2} \mathrm{O}$ \\
$\mathbf{6 5}$ & $3-\mathrm{Cl}$ & 74 & $4-\mathrm{MeS}$ \\
$\mathbf{6 6}$ & $2,6-\mathrm{Cl}_{2}$ & $\mathbf{7 5}$ & $4-\mathrm{NC}$ \\
\hline
\end{tabular}

Figure 2. Structures of hydantoins 51-75.

\section{RESULTS AND DISCUSSION}

Correlation Studies on the Lipophilicities of the Whole Set. The lipophilicities $(S)$ of 73 hydantoins reported by Scholl et al. ${ }^{2}$ have been correlated with the molecular descriptors employing CODESSA software via the heuristic and the best multilinear regression methods. From the list of 75 hydantoins whose structures have been given by Scholl et al., ${ }^{2}$ two had to be excluded from the correlations as no RP-HPLC retention times were available.

The heuristic correlations performed for the whole set afforded single-, two-, and three-parameter equations as listed in Table 2, which correspond to the optimum correlations as judged from the values of $R^{2}$, the Fisher criteria, and the Student's $t$-values. Likewise, the results of the BMLR are recorded in Table 3.

The single-parameter correlation equation (eq 2) from Table 2 is already significantly improved in comparison with the correlation of the lipophilicities $(S)$ of hydantoins with the Connolly surface areas $(A)^{10}$ in the single-parameter equation (eq 1) reported by Scholl et al. ${ }^{2}$ The best twoparameter equation (eq 3 ) was found by the heuristic method
(Table 2), while the best three-parameter equation (eq 4) emerged from the BMLR analysis.

$$
\begin{gathered}
S=-(0.0014 \pm 0.0001) S_{\text {tot }}+(0.0103 \pm 0.0154) \\
\left(R^{2}=0.6728, n=73, F=146.0, s^{2}=0.0002\right) \\
S=-(0.0204 \pm 0.0013) S_{\text {rot }}+ \\
\quad(0.0185 \pm 0.0028) \mathrm{RE}_{\mathrm{CC}, \min }+(0.2500 \pm 0.0330) \\
\left(R^{2}=0.7976, n=73, F=137.9, s^{2}=0.002\right) \\
S=-(0.01909 \pm 0.00105) S_{\text {rot }}+ \\
(0.00224 \pm 0.00038) \mathrm{CSA}_{\mathrm{N}}+ \\
(0.1851 \pm 0.0242) \mathrm{CI}_{\text {min }}-(0.5409 \pm 0.1113) \\
\left(R^{2}=0.8423, n=73, F=122.8, s^{2}=0.001\right)
\end{gathered}
$$

In these equations, $S_{\text {tot }}$ and $S_{\text {rot }}$ correspond to total and rotational entropy respectively, $\mathrm{RE}_{\mathrm{CC} \text {,min }}$ is the minimum resonance energy for a $\mathrm{C}-\mathrm{C}$ bond, $\mathrm{CSA}_{\mathrm{N}}$ is the charged solvent accessible surface area of nitrogen atoms, and $\mathrm{CI}_{\mathrm{min}}$ is the minimum Coulombic interaction for a $\mathrm{C}-\mathrm{N}$ bond. 
Table 2. Correlations of Lipophilicities of Hydantoins by Heuristic Methods

\begin{tabular}{|c|c|c|c|c|c|c|c|c|}
\hline no. $P$ & $R^{2}$ & $\mathrm{~F}$ & $s^{2}$ & & B & $\Delta B$ & $\mathrm{t}$ & name of descriptor \\
\hline \multicolumn{9}{|c|}{ Whole Set $(n=73)$} \\
\hline \multirow[t]{2}{*}{1} & 0.6728 & 146.0 & 0.0002 & 0 & -0.0103 & 0.0154 & -0.67 & intercept \\
\hline & & & & 1 & -0.0014 & 0.0001 & -12.1 & total entropy $(300 \mathrm{~K})$ \\
\hline \multirow[t]{3}{*}{2} & 0.7976 & 137.9 & 0.0002 & 0 & 0.2500 & 0.0330 & 7.59 & intercept \\
\hline & & & & 1 & -0.0204 & 0.0013 & -15.8 & rotational entropy $(300 \mathrm{~K})$ \\
\hline & & & & 2 & 0.0185 & 0.0028 & 6.69 & min resonance energy for a $\mathrm{C}-\mathrm{C}$ bond \\
\hline \multirow[t]{4}{*}{3} & 0.8266 & 109.6 & 0.0001 & 0 & 3.3070 & 0.49654 & 6.66 & intercept \\
\hline & & & & 1 & -0.01921 & 0.00123 & -15.6 & rotational entropy $(300 \mathrm{~K})$ \\
\hline & & & & 2 & -0.00873 & 0.00142 & -6.14 & max electron attraction for a $\mathrm{N}$ atom \\
\hline & & & & 3 & 0.007596 & 0.00203 & 3.73 & CSA-2 of $\mathrm{N}$ atoms \\
\hline \multicolumn{9}{|c|}{ Subset A $(n=54)$} \\
\hline \multirow[t]{2}{*}{1} & 0.7597 & 164.4 & 0.0002 & 0 & 0.4735 & 0.0518 & 9.14 & intercept \\
\hline & & & & 1 & -0.02034 & 0.00159 & -12.8 & rotational entropy $(300 \mathrm{~K})$ \\
\hline \multirow[t]{3}{*}{2} & 0.8073 & 106.9 & 0.0001 & 0 & 0.4308 & 0.0483 & 8.9 & intercept \\
\hline & & & & 1 & -0.0193 & 0.0015 & -13.2 & rotational entropy $(300 \mathrm{~K})$ \\
\hline & & & & 2 & 0.00104 & 0.00029 & 3.55 & surface area of $\mathrm{N}$ atoms \\
\hline \multirow[t]{4}{*}{3} & 0.8438 & 90.1 & 0.0001 & 0 & -0.29088 & 0.21557 & -1.35 & intercept \\
\hline & & & & 1 & -0.01877 & 0.00134 & -14.0 & rotational entropy $(300 \mathrm{~K})$ \\
\hline & & & & 2 & 0.00116 & 0.00027 & 4.33 & surface area of $\mathrm{N}$ atoms \\
\hline & & & & 3 & 0.13480 & 0.03942 & 3.42 & min. Coulombic interaction for a $\mathrm{C}-\mathrm{N}$ bond \\
\hline \multicolumn{9}{|c|}{ Subset B $(n=19)^{a}$} \\
\hline \multirow[t]{2}{*}{1} & 0.7379 & 47.9 & 0.0001 & 0 & 0.5537 & 0.1104 & 5.02 & intercept \\
\hline & & & & 1 & -0.02183 & 0.00316 & -6.92 & rotational entropy $(300 \mathrm{~K})$ \\
\hline \multirow[t]{3}{*}{2} & 0.8819 & 59.8 & 0.0001 & 0 & -0.33405 & 0.02304 & -14.5 & intercept \\
\hline & & & & 1 & -0.000833 & 0.000080 & -10.4 & zero-point vibrational energy \\
\hline & & & & 2 & 3.7249 & 0.40574 & 9.18 & PCSA of $\mathrm{H}$ atoms \\
\hline
\end{tabular}

${ }^{a}$ In view of the limited data sets, three-parameter correlations are not included for subset B.

Table 3. Correlations of Lipophilicities of Hydantoins by Best Multilinear Regression

\begin{tabular}{|c|c|c|c|c|c|c|c|c|}
\hline no. $P$ & $R^{2}$ & $\mathrm{~F}$ & $s^{2}$ & & B & $\Delta B$ & $\mathrm{t}$ & name of descriptor \\
\hline \multicolumn{9}{|c|}{ Whole Set $(n=73)$} \\
\hline \multirow[t]{3}{*}{2} & 0.7085 & 85.06 & 0.0002 & 0 & 0.2819 & 0.0389 & 7.24 & intercept \\
\hline & & & & 1 & -0.0145 & 0.00117 & -12.4 & rotational entropy $(300 \mathrm{~K})$ \\
\hline & & & & 2 & 0.00156 & 0.00050 & 3.11 & CSA of $\mathrm{N}$ atoms \\
\hline \multirow[t]{4}{*}{3} & 0.8423 & 122.8 & 0.0001 & 0 & -0.5409 & 0.1113 & -4.86 & intercept \\
\hline & & & & 1 & -0.01909 & 0.00105 & -18.2 & rotational entropy $(300 \mathrm{~K})$ \\
\hline & & & & 2 & 0.002241 & 0.00038 & 5.85 & CSA of $\mathrm{N}$ atoms \\
\hline & & & & 3 & 0.1851 & 0.02419 & 7.65 & min Coulombic interaction for a $\mathrm{C}-\mathrm{N}$ bond \\
\hline \multicolumn{9}{|c|}{ Subset A $(n=54)$} \\
\hline 2 & 0.8073 & 106.9 & 0.0001 & 0 & 0.4308 & 0.0483 & 8.91 & intercept \\
\hline & & & & 1 & -0.0193 & 0.00146 & -13.2 & rotational entropy $(300 \mathrm{~K})$ \\
\hline \multirow{5}{*}{3} & & & & 2 & 0.00104 & 0.00029 & 3.55 & $\mathrm{SA}$ of $\mathrm{N}$ atoms \\
\hline & 0.8452 & 91.02 & 0.0001 & 0 & -3.9227 & 0.2199 & -1.78 & intercept \\
\hline & & & & 1 & -0.01916 & 0.00132 & -14.6 & rotational entropy $(300 \mathrm{~K})$ \\
\hline & & & & 2 & 0.1570 & 0.0402 & 3.90 & min Coulombic interaction for a $\mathrm{C}-\mathrm{N}$ bond \\
\hline & & & & 3 & 0.002307 & 0.00052 & 4.40 & CSA of $\mathrm{N}$ atoms \\
\hline \multicolumn{9}{|c|}{ Subset B $(n=19)^{a}$} \\
\hline 2 & 0.8456 & 43.8 & 0.0001 & 0 & -0.1842 & 0.0833 & -6.50 & intercept \\
\hline & & & & 1 & -0.00241 & 0.00027 & -8.86 & total heat capacity $(300 \mathrm{~K})$ \\
\hline & & & & 2 & 2.0161 & 0.37672 & 5.35 & PCSA of $\mathrm{H}$ atoms \\
\hline
\end{tabular}

${ }^{a}$ In view of the limited data sets, three-parameter correlations are not included for subset B.

An examination of the data presented in Tables 2 and 3 reveals that the entropy is the most significant contributory factor for the lipophilicity, besides the other factors, viz., minimum resonance energy for a $\mathrm{C}-\mathrm{C}$ bond, the maximum electron attraction for a nitrogen atom, and the charged solvent accessible surface area of the hydantoins.

The integrity of the selected descriptors in eq 4 is depicted in Table 3. The assumption about normal law for distribution of the dependent variable allows one to draw the conclusion about real error of prediction. The standard error $s^{2}<0.0002$ compared to the error in the model is 0.028 units of lipophilicity with $95 \%$ reliability; for comparison the range of the dependent variable is 0.12 .
That the above factors could influence the lipophilicity is understandable in terms of rigidity of the molecule (the second descriptor in eq 3) and probability and energetics involved in the formation of hydrogen bonding and other interactions (remaining descriptors).

The lipophilicities of the hydantoins correlate better with either the total entropy, $S_{\text {tot }}$, or its rotational component, $S_{\text {rot }}$, than with the surface area, $A$. The influence of entropy on the lipophilicity is explicable on the basis that the larger the entropy, the more difficult could be the interaction with other entities that could have a bearing on the chemical potential involved in the partition phenomenon. This is also evident from the negative sign of the partition coefficient, B, for 




Figure 3. Plot of calculated vs experimental lipophilicities based on eq 4.

the entropy term in all correlations. In fact, in the structureproperty correlations of lipophilicities of organic compounds as measured by retention times in a nonpolar stationary phase in GLC, the entropy factor has been found to be among the contributory factors. ${ }^{11}$

The positive sign of the partition coefficient, B, related to the charged solvent accessible surface area of nitrogens is also explainable since the larger the surface area of the atoms involved, the greater could be the interaction. As a representative example, the correlation between the observed and calculated lipophilicities of the whole set on the basis of the three-parameter equation (eq 4) is depicted in Figure 3.

Correlation Studies on the Lipophilicities of Two Subsets of Hydantoins. The finding that entropy is a factor that influences significantly the lipophilicity of hydantoins led us to divide the structures of the series of hydantoins used in the present study into two subsets, A and B. Hydantoins in subset A (total 54, 2-42 and 44-56) have a saturated carbon at the 5-position, which carries either one or two alkyl/aryl groups, which may contribute significantly to the entropy. Subset B, the other 19 hydantoins (57-75), with the 5-carbon unsaturated and attached to an arylidene moiety, has motion of the groups considerably restricted. Hence, the QSPR correlations have been performed for these two subsets separately employing both the heuristic and BMLR methods, and the results are also included in Tables 2 and 3.

For subset A, entropy is again a significant contributing factor to lipophilicity along with surface area of nitrogen atoms and minimum Coulombic interaction for a $\mathrm{C}-\mathrm{N}$ bond (Table 2). The descriptor coefficient for the rotational entropy term in the correlations of subset A is indeed of the same magnitude as for the whole set of hydantoins. The best multilinear correlation results reported in Table 3 are also in accord with that obtained from heuristic correlations (Table 2 ), showing the involvement of rotational entropy, surface area/charged surface area of nitrogens, and minimum Coulombic interaction for a $\mathrm{C}-\mathrm{N}$ bond.

The heuristic correlations of subset B presented in Table 2 show that a two-parameter correlation, with the zero-point vibrational energy and positively charged solvent-accessible surface area related to hydrogen atoms as the contributing factors, is statistically more significant than the single- parameter correlation. The results obtained from the best multilinear regression analysis of the lipophilicities of the subset B are in accord with those from the heuristic method. Both heuristic and BMLR two-parameter correlations reveal the involvement of a common factor, viz., positively charged solvent-accessible surface area of hydrogen atoms, the other being either the zero-point vibrational energy (heuristic) or the total heat capacity (BMLR). These two factors, which are probably interrelated with negative signs for their weighting factors, have similar influence on the lipophilicity.

Cross-Validation. Cross-validation of the three-parameter correlation (eq 4) for the whole set was performed in the following manner. The whole set of 73 compounds was divided into three groups: compounds $\mathbf{2}, \mathbf{5}, \mathbf{8}$, etc. formed one group 1 , compounds $\mathbf{3}, \mathbf{6}, \mathbf{9}$, etc. formed group 2 , and compounds 4, 7, 10, etc. formed group 3. Three subsets, $X$, $\mathrm{Y}$, and $\mathrm{Z}$, were formed from these groups by combining the groups 1 and 2, 2 and 3, and 1 and 3, respectively. The descriptors that were obtained in the best heuristic threeparameter correlation for the whole set of hydantoins were selected. With these descriptors, the lipophilicities of subsets $\mathrm{X}, \mathrm{Y}$, and $\mathrm{Z}$ were predicted and correlated with their experimental lipophilicities, which afforded $R^{2}$ values of $0.836,0.850$, and 0.834 , respectively. The coefficients of the descriptors for sets $\mathrm{X}, \mathrm{Y}$, and $\mathrm{Z}$ were recorded. The lipophilicities for group 1 were then predicted using the descriptor partition coefficients from subset Y (generated from groups 2 and 3). Similarly, group 2 and group 3 lipophilicities were predicted using the partition coefficients from subsets $Z$ and $X$, respectively. All the predicted lipophilicities for group $\mathrm{X}, \mathrm{Y}$, and $\mathrm{Z}$ were combined and correlated with the experimental lipophilicities of the whole set. This afforded a correlation coefficient of 0.829 compared to that found in the original three-parameter correlation (0.842) obtained by the heuristic method.

\section{CONCLUSIONS}

This study has provided improved correlations of the lipophilicity data of hydantoins with the molecular descriptors using the CODESSA program. It is important to note that for the two subsets of hydantoins different descriptors explain the variation in the lipophilicity. This study will be useful in predicting new hydantoins belonging to subsets $\mathrm{A}$ and $\mathrm{B}$ with maximum lipophilicity values and hence with possible biological application.

\section{REFERENCES AND NOTES}

(1) Lopez, A. C.; Trigo, C. G. The Chemistry of Hydantoins. Advances in Heterocyclic Chemistry; Katritzky A. R., Ed.; Academic Press: New York, 1985; Vol. 38, pp 177-228.

(2) Scholl, S.; Koch, A.; Henning, D.; Kempter, G.; Kleinpeter, E. The Influence of Structure and Lipophilicity of Hydantoin Derivatives on Anticonvulsant Activity. Struct. Chem. 1999, 10, 355-366.

(3) (a) Park, K.-H.; Olmstead, M. M.; Kurth, M. J. Diastereoselective Synthesis of Cyclopentanoids with Hydantoin and Isoxazoline Substituents. J. Org. Chem. 1998, 63, 113-117. (b) Gong, Y.-D.; Sohn, H.-Y.; Kurth, M. J. Microwave-Mediated Intramolecular Carbanilide Cyclization to Hydantoins Employing Barium Hydroxide Catalysis. J. Org. Chem. 1998, 63, 4854-4856. (c) Park, K.-H.; Olmstead, M. M.; Kurth, M. J. Diastereoselective Solid-Phase Synthesis of Novel Hydantoin- and Isoxazoline-Containing Heterocycles. J. Org. Chem. 1998, 63, 6579-6585.

(4) (a) Kleinpeter, E. The Structure of Hydantoins in Solution and in the Solid State. Struct. Chem. 1997, 8, 161-173. (b) Benassi, R.; Bregulla, A.; Henning, D.; Heydenreich, M.; Kempter, G.; Kleinpeter, E.; 
Taddei, F. NMR spectroscopic and theoretical structural analysis of 5-benzyl substituted hydantoins in solution. J. Mol. Struct. 1999, 475 105-112. (c) Benassi, R.; Bregulla, A.; Friedrich, A.; Henning, D.; Heydenreich, M.; Mickler, W.; Kleinpeter, E.; Kempter, G.; Schilde, U.; Taddei, F. NMR spectroscopic and theoretical structural study of 5-exo-methylene-substituted hydantoins. J. Mol. Struct. 1998, 441, 4762.

(5) Braumann, T. Determination of hydrophobic parameters by reversedphase liquid chromatography: Theory, experimental techniques, and application in studies on quantitative structure-activity relationships. J. Chromatogr. 1986, 373, 191-225.

(6) (a) Katritzky, A. R.; Lobanov, V. S.; Karelson, M. QSPR: The Correlation and Quantitative Prediction of Chemical and Physical Properties from Structure. Chem. Soc. Rev. 1995, 279-287. (b) Karelson, M.; Lobanov, V. S.; Katritzky, A. R. Quantum-Chemical Descriptors in QSAR/QSPR Studies. Chem. Rev. 1996, 96, 10271043. (c) Karelson, M.; Maran, U.; Wang, Y.; Katritzky, A. R. QSPR and QSAR models derived using large descriptor spaces. A review of
CODESSA applications. Collect. Czech. Chem. Commun. 1999, 64, 1551-1571.

(7) Dewar, M. J. S.; Zoebisch, E. G.; Healy, E. F.; Stewart, J. J. P. AM1: A New General Purpose Quantum Mechanical Molecular Model. J. Am. Chem. Soc. 1985, 107, 3902-3909.

(8) Dewar, M. J. S.; et al. MOPAC 7.0 for UNIX; Quantum Chemistry Program Exchange, Project 688.

(9) Katritzky, A. R.; Lobanov, V. S.; Karelson, M. CODESSA: Reference Manual; Version 2; University of Florida, 1996.

(10) Connolly, M. L. Solvent-Accessible Surfaces of Proteins and Nucleic Acids. Science 1983, 221, 709-713.

(11) Katritzky, A. R.; Ignatchenko, E. S.; Barcock, R. A.; Lobanov, V. S.; Karelson, M. Prediction of Gas Chromatographic Retention Times and Response Factors Using a General Quantitative-Property Relationship Treatment. Anal. Chem. 1994, 66, 1799-1807. 